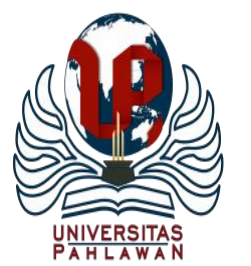

Jurnal Abdidas Volume 2 Nomor 3 Tahun 2021 Halaman 705-712

JURNAL ABDIDAS

http://abdidas.org/index.php/abdidas

\title{
Peningkatan Pengetahuan Remaja untuk Deteksi Dini Kanker Payudara dengan Edukasi dan Pelaksanaan Pemeriksaan Payudara Sendiri (Sadari) di Yayasan Perguruan Budi Agung Medan Tahun 2021
}

\author{
Jitasari Tarigan Sibero ${ }^{1 凶}$, Afrahul Padilah Siregar ${ }^{2}$, Aida Fitria ${ }^{3}$ \\ Kebidanan, Institut Kesehatan Helvetia, Indonesia ${ }^{1,2,3}$ \\ E-mail: jitasari76@gmail.com ${ }^{1}$, afrahul.padilah@gmail.com ${ }^{2}$, aidafitria@ helvetia.ac.id ${ }^{3}$
}

\begin{abstract}
Abstrak
Yayasan Kanker Payudara Indonesia menyatakan ada kecenderungan penurunan usia penderita kanker payudara di Indonesia terutama pada remaja. Kasus yang pernah ditangani dilaporkan berusia 15 tahun. Salah satu upaya yang bisa dilakukan untuk mengendalikan kanker payudara adalah dengan melakukan pencegahan primer, seperti pengendalian faktor risiko dan peningkatan komunikasi, informasi, dan edukasi. Pencegahan sekunder dilakukan melalui deteksi dini kanker payudara yaitu pemeriksaan payudara sendiri (Sadari). Sadari merupakan metode pemeriksaan sederhana dan paling mudah yang dapat dilakukan dengan menggunakan jari-jari tangan. Kanker payudara yang ditemukan pada fase dini kemungkinan dapat sembuh 95\%. Metode yang digunakan untuk pemecahan masalah dalam kegiatan ini adalah penyuluhan yang dilanjutkan dengan praktik dan diskusi. Pengetahuan responden pretest terbanyak kurang sebesar $60 \%$, diikuti responden yang berpengetahuan cukup dan baik masing-masing sebesar 33,3\% dan 6,7\%, sedangkan pengetahuan responden pada post-test terbanyak adalah baik sebesar $80 \%$, berpengetahuan cukup sebesar $20 \%$, dan tidak ada responden yang berpengetahuan kurang. Penyuluhan yang berkelanjutan mengenai Sadari dan cara melakukan Sadari dengan benar dan rutin sebagai deteksi dini kanker payudara perlu dilakukan untuk meningkatkan pengetahuan masyarakat mengenai pentingnya deteksi dini kanker payudara.
\end{abstract}

Kata kunci: kanker payudara, sadari, penyuluhan

\section{Abstract}

The Indonesian Breast Cancer Foundation states that there is a tendency to decrease the age of breast cancer sufferers in Indonesia, especially in adolescents. Cases that have been handled are reported to be 15 years old. One of the efforts that can be done to control breast cancer is to carry out primary prevention such as controlling risk factors and increasing communication, information and education. Secondary prevention is done through early detection of breast cancer, namely breast self-examination (Aware). Realize is the simplest and easiest method of checking that can be done using the fingers. Breast cancer found at an early stage has a $95 \%$ chance of being cured. The method used for problem solving in this activity is counseling followed by practice and discussion. The knowledge of the most pre-test respondents was less by $60 \%$, followed by respondents who had sufficient and good knowledge respectively by $33.3 \%$ and $6.7 \%$, while the knowledge of respondents in the post-test was mostly good at $80 \%$, knowledgeable enough by 20\%, and there are no respondents who are less knowledgeable. Continuous counseling on Awareness and how to do Awareness correctly and regularly as an early detection of breast cancer needs to be done to increase public knowledge about the importance of early detection of breast cancer.

Keywords: trainingbreast cancer, bse, counseling

Copyright (c) 2021 Jitasari Tarigan Sibero, Afrahul Padilah Siregar, Aida Fitria

$\triangle$ Corresponding author

Address : Institut Kesehatan Helvetia

Email : jitasari76@gmail.com

ISSN 2721- 9224 (Media Cetak)

DOI : https://doi.org/10.31004/abdidas.v2i3.351

ISSN 2721- 9216 (Media Online) 
706 Peningkatan Pengetahuan Remaja untuk Deteksi Dini Kanker Payudara dengan Edukasi dan Pelaksanaan Pemeriksaan Payudara Sendiri (Sadari) di Yayasan Perguruan Budi Agung Medan Tahun 2021- Jitasari Tarigan Sibero, Afrahul Padilah Siregar, Aida Fitria

DOI: https://doi.org/10.31004/abdidas.v2i3.351

\section{PENDAHULUAN}

Penyakit kanker payudara merupakan penyebab utama kematian di antara semua penyakit kanker yang dialami wanita di Indonesia. Penyakit kanker merupakan salah satu masalah kesehatan di seluruh dunia, meningkatnya angka kematian akibat kanker payudara salah satunya karena terdeteksi pada stadium lanjut.

Saat ini penyakit tidak menular, termasuk kanker menjadi masalah kesehatan utama baik di dunia maupun di Indonesia. Menurut data World Health Organization (WHO) tahun 2013, insiden kanker meningkat dari 12,7 juta kasus tahun 2008 menjadi 14,1 juta kasus tahun 2012. Sedangkan jumlah kematian meningkat dari 7,6 juta orang tahun 2008 menjadi 8,2 juta pada tahun 2012. Kanker menjadi penyebab kematian nomor 2 di dunia sebesar $13 \%$ setelah penyakit kardiovaskular. Diperkirakan pada 2030 insiden kanker dapat mencapai 26 juta orang dan 17 juta di antaranya meninggal akibat kanker, terlebih untuk negara miskin dan berkembang kejadiannya akan lebih cepat (D. RI 2006).

Globocan menyebutkan bahwa negaranegara di Asia memiliki kontribusi terbesar terhadap kasus kanker di seluruh dunia. Hal ini bisa disebabkan karena memang sebagian negara dengan populasi besar seperti Cina, India, dan Indonesia berada di Asia. Data Global Cancer Observatory tahun 2018 menunjukkan angka kejadian penyakit kanker di Indonesia (136,2/100.000 penduduk) berada pada urutan 8 di Asia Tenggara, sedangkan di Asia urutan ke 23. Angka kejadian untuk perempuan yang tertinggi adalah kanker payudara yaitu sebesar 42,1 per 100.000 penduduk dengan rata-rata kematian 17 per 100.000 penduduk yang diikuti kanker leher rahim sebesar 23,4 per 100.000 penduduk dengan rata-rata kematian 13,9 per 100.000 penduduk (Kementerian Kesehatan Indonesia Pusat Data dan Informasi 2015).

Kanker terdiri dari beberapa jenis tergantung dari organ tubuh yang menjadi tempat pertumbuhan sel dan jaringan kanker tersebut. Sampai dengan tahun 2018, kejadian kanker paru $(11,6 \%)$, payudara $(11,6 \%)$, prostat $(7,1 \%)$, kolorektal (10,2\%), dan lambung 1,7\%) merupakan jenis kanker yang paling banyak ditemukan di dunia. Kanker paru menempati peringkat pertama dalam jumlah kasus baru sebesar 2,094 juta kasus di seluruh dunia. Jumlah kasus baru tertinggi berikutnya adalah kanker payudara, kanker kolorektal, kanker prostat, dan kanker lambung. Besarnya jumlah kasus baru yang ditemukan dapat dipengaruhi oleh kualitas sistem deteksi dini tiap jenis kanker. Kematian akibat kanker tertinggi di dunia adalah kanker paru sebesar 1,8 kematian yang diikuti oleh kematian akibat kanker kolorektal (9,2\%), kanker lambung $(8,2 \%)$, kanker hati, dan kanker payudara $(6,6 \%)$. Kematian akibat kanker di antaranya ditentukan oleh prognosis jenis kanker yang diidap oleh pasien. Kualitas pelayanan kesehatan yang diberikan pada proses pengobatan juga mempengaruhi prognosis pasien (I. P. D. D. I. K. K. RI 2019).

Menurut Riset Kesehatan Dasar (Riskesdas) tahun 2018, prevalensi tumor/kanker di Indonesia 
707 Peningkatan Pengetahuan Remaja untuk Deteksi Dini Kanker Payudara dengan Edukasi dan Pelaksanaan Pemeriksaan Payudara Sendiri (Sadari) di Yayasan Perguruan Budi Agung Medan Tahun 2021- Jitasari Tarigan Sibero, Afrahul Padilah Siregar, Aida Fitria

DOI: https://doi.org/10.31004/abdidas.v2i3.351

menunjukkan adanya peningkatan dari 1,4 per 1.000 penduduk di tahun 2013 menjadi 1,79 per 1.000 penduduk pada tahun 2018. Prevalensi kanker tertinggi adalah di provinsi DI Yogyakarta sebanyak 4,86 per 1.000 penduduk, diikuti Sumatera Barat 2,47 per 1.000 penduduk dan Gorontalo 2,44 per 1.000 penduduk (Kemenskes 2016).

Data Divisi Bedah Onkologi RSUP $\mathrm{H}$. Adam Malik Medan, terdapat 1.427 penderita kanker payudara pada kurun waktu 2011- 2013. Berdasarkan data survei awal di RSUP H. Adam Malik Medan tahun 2013-1015 terdapat 1710 kasus dengan rincian sebagai berikut, penderita kanker payudara pada tahun 2013 sebanyak 325 pasien, pada tahun 2014 sebanyak 444 pasien dan pada tahun 2015 sebanyak 941 pasien (Rekam Medik RSUP H. Adam Malik Medan). Hasil penelitian yang dilakukan oleh Tri Budi Setiawan Nasution dengan judul Angka Kejadian Kanker Payudara pada Wanita Usia Sangat Muda Kurang dari $\leq 35$ Tahun di RSUP H. Adam Malik Medan mendapatkan angka kejadian penderita kanker payudara usia sangat muda $\leq 35$ tahun yang berobat ke RSUP H. Adam Malik Medan sejak 1 Januari 2013- 31 Desember 2017 sebesar 9,08\% (Nasution 2018).

Masa remaja merupakan masa peralihan antara masa kanak-kanak dan masa dewasa yang dimulai pada saat terjadinya kematangan seksual yaitu antara usia 11 atau 12 tahun sampai dengan 20 tahun, menjelang masa dewasa muda. Pada masa ini terjadi kecepatan pertumbuhan dan perkembangan fisik, mental, emosional serta sosial
(Soetjiningsih 2004). Yayasan Kanker Payudara Indonesia menyatakan ada kecenderungan penurunan usia penderita kanker payudara di Indonesia terutama pada remaja. Kasus yang pernah ditangani dilaporkan berusia 15 tahun. Kecenderungan ini diperkirakan karena gaya hidup terutama makanan yang tidak sehat (junk food), kurang konsumsi sayur dan buah, merokok dan alkohol. Pada masa remaja, komposisi diet saat pubertas yang tidak seimbang serta gaya hidup yang tidak sehat juga memiliki peran besar sebagai penyebab kanker payudara di kemudian hari. Hal ini disebabkan, gizi merupakan salah satu faktor yang mempengaruhi kadar esterogen dan estradiol dalam tubuh (Kementerian Kesehatan Indonesia Pusat Data dan Informasi 2015).

Salah satu upaya yang bisa dilakukan untuk mengendalikan kanker payudara adalah dengan melakukan pencegahan primer seperti pengendalian faktor risiko dan peningkatan komunikasi, informasi dan edukasi. Pencegahan sekunder dilakukan melalui deteksi dini kanker payudara yaitu pemeriksaan payudara sendiri (Sadari) (I. P. D. D. I. K. K. RI 2019). Sadari merupakan metode pemeriksaan sederhana dan paling mudah yang dapat dilakukan dengan mengagungkan jari-jari tangan. Kanker payudara yang ditemukan pada fase dini kemungkinan dapat sembuh 95\% (Kementerian Kesehatan Indonesia Pusat Data dan Informasi 2015). Sadari dilakukan di depan cermin dengan cara inspeksi untuk melihat perubahan bentuk payudara dan palpasi melalui perabaan untuk mendeteksi adanya massa (Kumalasari and Andhyantoro 2012). 
708 Peningkatan Pengetahuan Remaja untuk Deteksi Dini Kanker Payudara dengan Edukasi dan Pelaksanaan Pemeriksaan Payudara Sendiri (Sadari) di Yayasan Perguruan Budi Agung Medan Tahun 2021- Jitasari Tarigan Sibero, Afrahul Padilah Siregar, Aida Fitria

DOI: https://doi.org/10.31004/abdidas.v2i3.351

Saat ini ada kecenderungan kanker payudara dialami oleh perempuan dengan usia 15-20 tahun, ini berarti tidak ada kata terlalu dini bagi perempuan dengan usia 15-20 tahun untuk mulai diberikan pendidikan untuk melakukan Sadari secara rutin (7-10 hari setelah haid) setiap bulan. Hasil penelitian Septiani terhadap siswa SMAN 62 Jakarta menunjukkan bahwa siswa yang berumur lebih dari 15 tahun memiliki peluang 1,637 kali untuk melakukan SADARI dibandingkan siswa yang berumur kurang dari 15 tahun. Hal ini dikarenakan usia termasuk dalam faktor predisposisi terjadinya perubahan perilaku yang mana dikaitkan dengan pematangan fisik dan psikis seseorang. Dengan melakukan pemeriksaan payudara sendiri sejak usia 15 tahun akan menurunkan tingkat kematian akibat kanker payudara sampai $20 \%$, sayangnya wanita yang melakukan Sadari masih rendah, yaitu sebesar 25\%-30\% (Septiani and Suara 2013).

Tindakan Sadari sangatlah penting untuk diterapkan, karena telah dibuktikan bahwa hampir 85\% kelainan pada payudara ditemukan pertama kali oleh penderita melalui penerapan Sadari yang benar (Oflah Yustina 2017). Upaya ini sangat penting, sebab apabila kanker payudara dapat dideteksi pada stadium dini dan diterapi secara tepat maka tingkat kesembuhan cukup tinggi mencapai $80-90 \%$. Deteksi dini dapat menekan angka kematian sebesar 25-30\%. Deteksi dini juga dapat meningkatkan kesembuhan penderita kanker payudara dengan penemuan dini, diagnosis dini, dan terapi dini (Rasjidi 2010).
Manfaat yang didapat dengan melakukan Sadari adalah dapat meningkatkan harapan hidup penderita kanker payudara karena dapat terdeteksi secara dini serta metode ini dapat dilakukan dengan mudah, murah dan sederhana. Pada pemeriksaan payudara sendiri ini hampir $85 \%$ benjolan abnormal ditemukan oleh penderita sendiri melalui pemeriksaan dengan langkah yang benar (Nisman 2011).

Wanita yang tidak melakukan Sadari dan sudah ditemukan keganasan pada payudaranya sebagian besar datang ke pelayanan kesehatan saat stadium lanjut sehingga pengobatannya tidak dapat adekuat atau tepat (Manuaba, 2009). Pasien yang terdeteksi pada stadium lanjut tidak bisa diterapi dengan operasi saja, tetapi harus dengan terapi radiasi atau kemoterapi dan angka kelangsungan hidupnya rendah, yaitu stadium I $85 \%$, stadium II 60-70\%, stadium III 30-50\%, stadium IV 15\% (Kementerian Kesehatan Indonesia Pusat Data dan Informasi 2015).

Dampak psikologis yang dialami oleh setiap orang berbeda-beda tergantung pada tingkat keparahan (stadium), jenis pengobatan yang dijalani dan karakteristik masing-masing penderita. Sekitar $30 \%$ penderita kanker mengalami permasalahan penyesuaian diri dan $20 \%$ di diagnosis mengalami depresi. Dampak psikologis yang sering dirasakan oleh pasien kanker payudara yaitu berupa ketidakberdayaan, kecemasan, rasa malu, harga diri menurun, stres dan amarah (Lubis 2009).

Meningkatkan pengetahuan remaja tentang Sadari sedini mungkin dapat membawa pengaruh 
709 Peningkatan Pengetahuan Remaja untuk Deteksi Dini Kanker Payudara dengan Edukasi dan Pelaksanaan Pemeriksaan Payudara Sendiri (Sadari) di Yayasan Perguruan Budi Agung Medan Tahun 2021- Jitasari Tarigan Sibero, Afrahul Padilah Siregar, Aida Fitria

DOI: https://doi.org/10.31004/abdidas.v2i3.351

baik bagi remaja hingga menjadi wanita dewasa nanti. Salah satu upaya yang dapat dilakukan untuk meningkatkan pengetahuan remaja dalam melakukan Sadari adalah dengan memberikan pendidikan kesehatan (Lestari and Sintari 2019). Pendidikan kesehatan merupakan sebuah langkah awal dalam peningkatan pengetahuan seseorang, karena dengan adanya pendidikan kesehatan dapat memberikan bekal ilmu pengetahuan kepada seseorang, tak terkecuali pendidikan kesehatan tentang pemeriksaan payudara sendiri karena dengan Sadari dapat menurunkan angka kejadian kanker payudara pada perempuan (Syaiful and Aristantia 2016).

Berdasarkan hasil penelitian Kumalasary, Triwahyuningsih dan Wijayanti, pendidikan kesehatan sangat efektif dalam meningkatkan pengetahuan remaja putri mengenai Sadari. Tingkat pengetahuan remaja putri sebelum pendidikan kesehatan tentang Sadari di SMAN 7 Cirebon sebanyak 28\% kurang, 68\% cukup dan $4 \%$ baik, sedangkan praktik remaja putri sebelum pendidikan kesehatan tentang Sadari sebanyak 96\% tidak kompeten dan 4\% kompeten. Tingkat pengetahuan remaja putri sesudah pendidikan kesehatan tentang Sadari sebanyak 0\% kurang, 8\% cukup dan $92 \%$ baik, sedangkan praktik remaja putri sesudah pendidikan kesehatan tentang Sadari sebanyak 0\% tidak kompeten dan 100\% kompeten (Kumalasary, Triwahyuningsih \& Wijayanti, 2019). Penulis melakukan review literatur untuk memperdalam metode pendidikan kesehatan pemeriksaan payudara sendiri dan hasil yang didapat dari penggunaan metode tersebut (Kumalasari and Andhyantoro 2012).

\section{METODE}

Metode yang digunakan untuk pemecahan masalah dalam kegiatan ini adalah penyuluhan yang dilanjutkan dengan praktik dan diskusi. Materi penyuluhan yang diberikan meliputi:

1. Apa itu kanker payudara

2. Penyebab

3. Gejala

4. Pemeriksaan payudara sendiri (Sadari)

5. Langkah-langkah melakukan Sadari

Khalayak sasaran yang dalam kegiatan ini adalah sekitar 30 orang remaja di Yayasan Perguruan Budi Agung Medan. Evaluasi yang dilakukan untuk menilai keberhasilan kegiatan ini terdiri dari evaluasi awal, evaluasi proses dan evaluasi akhir. Evaluasi awal dilakukan dengan memberikan pretest kepada peserta yang berisi pertanyaan-pertanyaan yang terkait dengan materi yang akan diberikan. Hasil dari evaluasi ini berupa nilai skor tiap peserta, yang merupakan hasil pembagian dari jawaban benar dengan total jumlah pertanyaan dikalikan 100. Evaluasi proses dilakukan dengan melihat tanggapan remaja melalui pertanyaan-pertanyaan yang diajukan ataupun umpan balik yang diberikan dalam diskusi. Evaluasi akhir dilakukan dengan memberikan post-test kepada peserta yang berisi pertanyaan-pertanyaan yang sama yang telah diberikan pada pretest. Skor nilai post-test dibandingkan dengan skor nilai pretest. Apabila nilai post-test lebih tinggi dari nilai pretest, maka 
710 Peningkatan Pengetahuan Remaja untuk Deteksi Dini Kanker Payudara dengan Edukasi dan Pelaksanaan Pemeriksaan Payudara Sendiri (Sadari) di Yayasan Perguruan Budi Agung Medan Tahun 2021- Jitasari Tarigan Sibero, Afrahul Padilah Siregar, Aida Fitria

DOI: https://doi.org/10.31004/abdidas.v2i3.351

kegiatan penyuluhan yang diberikan berhasil meningkatkan pengetahuan masyarakat.

Tabel 1. Perbandingan Pengetahuan Remaja tentang Sadari

\begin{tabular}{ccc}
\hline \multicolumn{2}{c}{ Pengetahuan } & \multirow{2}{*}{ p value } \\
\cline { 1 - 2 } Pretest & Post-Test & \\
\hline Mean \pm SD & Mean \pm SD & \\
\hline $1,47 \pm 0,629$ & $2,80 \pm 0,407$ & 0,000 \\
\hline
\end{tabular}

Dari tabel di atas terlihat bahwa rata-rata pengetahuan responden sebelum dilakukan penyuluhan 1,47 dengan standar deviasi 0,629 dan setelah dilakukan penyuluhan dan praktik pemeriksaan payudara sendiri (Sadari) didapat rata-rata pengetahuan responden 2,80 dengan standar deviasi 0,407, sehingga dapat disimpulkan terjadi peningkatan pengetahuan remaja sebesar 1,33 dengan nilai $p=0,000$.

\section{HASIL DAN PEMBAHASAN}

Pada hari Selasa tanggal 25 Mei 2021 dilaksanakan kegiatan pengabdian kepada masyarakat di Yayasan Perguruan Budi Agung. Jumlah peserta yang mengikuti kegiatan pengabdian kepada masyarakat sebanyak 30 orang.

Kegiatan pengabdian kepada masyarakat dibantu oleh 2 dosen dan 2 mahasiswa sehingga kegiatan ini berdampak positif kepada peserta dan pelaksana kegiatan.

Sebelum dilakukan kegiatan, peserta mengisi daftar hadir dan kami memberikan juga lembaran kuesioner pretest kepada peserta, berupa kuesioner yang berisi pertanyaan pertanyaan mengenai materi yang akan diberikan. Hasil dari evaluasi ini berupa nilai skor tiap peserta yang dihasilkan dari jumlah jawaban benar dibagi dengan total jumlah pertanyaan dikali seratus. Evaluasi proses juga kami lakukan selama kegiatan dengan melihat tanggapan peserta melalui tanya jawab dan jalannya diskusi.

Selanjutnya dilakukan penyampaian materi oleh narasumber, para peserta menyimak dengan tekun dan antusias. Setelah narasumber selesai menyampaikan materi dibuka forum tanya jawab mengenai materi yang telah disampaikan. Ada lima pertanyaan yang diajukan oleh peserta yang dibagi dalam dua sesi. Setelah kegiatan berakhir dilakukan evaluasi akhir dengan memberikan posttest kepada peserta yang berisi pertanyaan pertanyan yang sama dengan pretest. Skor nilai pretest dibandingkan dengan skor nilai post-test untuk menilai ada tidaknya peningkatan pengetahuan peserta. Apabila terjadi peningkatan pengetahuan pada lebih dari $80 \%$ peserta, maka kegiatan penyuluhan dianggap berhasil. Remaja yang mengikuti kegiatan ini belum pernah mendapat penyuluhan atau pemberian materi mengenai Sadari secara rutin untuk deteksi dini kanker payudara sebelumnya. Setelah dilakukan seminar dan tanya jawab, kuesioner yang sama diberikan kembali kepada peserta. Hasil evaluasi didapat pengetahuan responden pretest terbanyak kurang sebesar $60 \%$, diikuti responden yang berpengetahuan cukup dan baik masing-masing sebesar $33,3 \%$ dan $6,7 \%$, sedangkan pengetahuan responden pada post-test terbanyak adalah baik sebesar $80 \%$, berpengetahuan cukup sebesar $20 \%$, dan tidak ada responden yang berpengetahuan kurang. Dari hasil pengamatan di lapangan, jelas 
711 Peningkatan Pengetahuan Remaja untuk Deteksi Dini Kanker Payudara dengan Edukasi dan Pelaksanaan Pemeriksaan Payudara Sendiri (Sadari) di Yayasan Perguruan Budi Agung Medan Tahun 2021- Jitasari Tarigan Sibero, Afrahul Padilah Siregar, Aida Fitria

DOI: https://doi.org/10.31004/abdidas.v2i3.351

bahwa kegiatan penyuluhan kesehatan ini perlu diadakan secara berkelanjutan agar pengetahuan masyarakat mengenai Sadari meningkat dan mau melaksanakan Sadari secara benar dan rutin untuk deteksi dini kanker payudara.
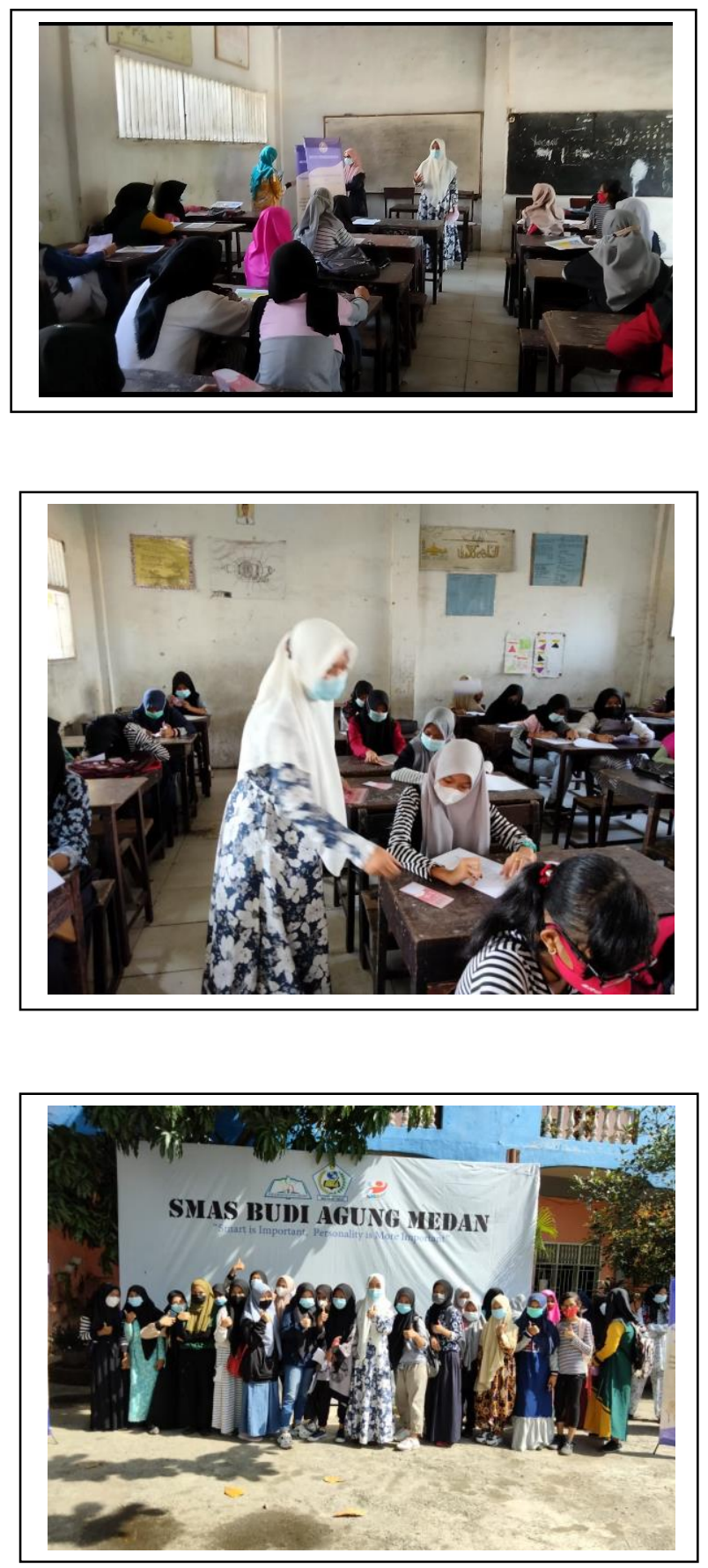

\section{SIMPULAN}

Setelah mendapatkan penyuluhan mengenai Sadari dan cara melakukan Sadari dengan benar sebagai deteksi dini kanker payudara, pengetahuan remaja mengalami peningkatan. Penyuluhan yang berkelanjutan mengenai Sadari dan cara melakukan Sadari dengan benar dan rutin sebagai deteksi dini kanker payudara perlu dilakukan untuk meningkatkan pengetahuan masyarakat mengenai pentingnya deteksi dini kanker payudara. Kegiatan penyuluhan bisa dilakukan melalui media-media yang telah ada seperti puskesmas, dan lain-lain.

\section{UCAPAN TERIMAKASIH}

Dalam pelaksanaan pengabdian masyarakat ini, tim pengabdi mendapatkan banyak bantuan dari LPPM dan Yayasan Institut Kesehatan Helvetia baik dari aspek moril maupun materil. Selain itu, tim pengabdi juga mengucapkan terima kasih kepada Yayasan Perguruan Budi Agusng beserta remaja yang telah bekerjasama dengan baik sehingga kegiatan dapat berjalan dengan lancar.

\section{DAFTAR PUSTAKA}

Kemenskes, R I. 2016. "Laporan Hasil Riset Kesehatan Dasar (Riskesdas)."

Kementerian Kesehatan Indonesia Pusat Data dan Informasi. 2015. Buletin Jendela Data Dan Informasi Kesehatan Situasi Penyakit Kanker.

Kumalasari, Intan, and Iwan Andhyantoro. 2012. "Kesehatan Reproduksi Untuk Mahasiswa Kebidanan Dan Keperawatan."

Lestari, R Tri Rahyuning, and Silvia Ni Nyoman Sintari. 2019. "PENGARUH PENDIDIKAN KESEHATAN DENGAN MEDIA AUDIO VISUAL TERHADAP PENGETAHUAN 
712 Peningkatan Pengetahuan Remaja untuk Deteksi Dini Kanker Payudara dengan Edukasi dan Pelaksanaan Pemeriksaan Payudara Sendiri (Sadari) di Yayasan Perguruan Budi Agung Medan Tahun 2021- Jitasari Tarigan Sibero, Afrahul Padilah Siregar, Aida Fitria

DOI: https://doi.org/10.31004/abdidas.v2i3.351

REMAJA PUTRI TENTANG

PEMERIKSAAN PAYUDARA SENDIRI

(SADARI)." Bali Medika Jurnal 6(1): 50-57.

Lubis, Namora Lumongga. 2009. Dukungan Sosial

Pada Pasien Kanker, Perlukah? USUpress. BOOK.

Nasution, Tri Budi Setiawan. 2018. "Angka Kejadian Dan Karakteristik Kanker Payudara Pada Wanita Usia Sangat Muda $\leq 35$ Tahun Di RSUP H. Adam Malik."

Nisman, Wenny Artanty. 2011. "Lima Menit Kenali Payudara Anda." Yogyakarta: Andi.

Oflah Yustina, Dkk. 2017. Kanker Payudara \& SADARI.

Rasjidi, Imam. 2010. "Epidemiologi Kanker Pada Wanita." Jakarta: Sagung Seto: 18-22.

RI, Depkes. 2006. "Direktorat Jenderal Pengendalian Penyakit Dan Penyehatan Lingkungan.” Buku pedoman nasional pemberantasan penyakit kusta. Jakarta.

RI, Infodatin Pusat Data Dan Informasi Kementerian Kesehatan. 2019. Beban Kanker Di Indonesia.

Septiani, Sari, and Mahyar Suara. 2013. "FaktorFaktor Yang Berhubungan Dengan Perilaku Pemeriksaan Payudara Sendiri (Sadari) Pada Siswa SMAN 62 Jakarta 2012.” Jurnal Ilmiah Kesehatan 5(1): 31-35.

Soetjiningsih, S. 2004. "Tumbuh Kembang Remaja Dan Permasalahannya." Sagung Seto. Jakarta 320.

Syaiful, Yuanita, and Riski Aristantia. 2016. "Pendidikan Kesehatan Pemeriksaan Payudara Sendiri Terhadap Perilaku Sadari Pada Remaja (Health Education Breast Self Examination Toward Bse Behavior In Adolescent)." Journals of Ners Community 7(2): 113-24. 